\title{
BMJ open Proximity to health services and child survival in low- and middle-income countries: a systematic review and meta-analysis
}

\author{
Yemisrach Behailu Okwaraji, ${ }^{1}$ Karen M Edmond ${ }^{2}$
}

To cite: Okwaraji YB, Edmond KM. Proximity to health services and child survival in low- and middle-income countries: a systematic review and meta-analysis. BMJ Open 2012;2:e001196.

doi:10.1136/

bmjopen-2012-001196

- Prepublication history and additional tables for this paper are available online. To view these files please visit the journal online (http://dx. doi.org/10.1136/ bmjopen-2012-001196).

Received 27 March 2012 Accepted 18 June 2012

This final article is available for use under the terms of the Creative Commons Attribution Non-Commercial 2.0 Licence; see http://bmjopen.bmj.com

\footnotetext{
${ }^{1}$ Faculty of Epidemiology and Population Health, London School of Hygiene and Tropical Medicine, London, UK

${ }^{2}$ School of Paediatrics and Child Health, University of Western Australia, Perth, Western Australia, Australia

\section{Correspondence to}

Yemisrach Behailu Okwaraji; yemisrach.okwaraji@Ishtm. ac.uk
}

\begin{abstract}
Objectives: Few studies have systematically examined the effects of barriers such as distance to health facilities on child survival in low- and middle-income countries. Our primary objective was to estimate the effect of proximity to health facilities on child survival in low- and middle-income countries. The secondary objective was to compare effects in different age categories (perinatal (28 weeks of gestation to 1 week of age), neonatal (0-27 days), infant (0-11 months) and child (0-59 months) mortality).

Design: A systematic review and meta-analysis was conducted of studies published from 1980 to 2012 that assessed the effect of proximity to health facilities on child survival in low- and middle-income countries. Synthesis was by random-effects meta-analysis, and variation between studies was investigated by metaregression.
\end{abstract}

Setting: Low- and middle-income countries.

Participants: 13 studies were included in the metaanalysis, 11 from low-income and two from middleincome countries and none were from remote areas.

Primary outcome measures: The primary outcome measures of interest were perinatal, neonatal, infant and child mortality.

Results: Overall, children who lived farthest from health facilities were more likely to die compared with those who lived closer (OR 1.32, 95\% Cl 1.19 to 1.47). This effect appeared stronger during the perinatal (OR 2.76, 95\% Cl 1.80 to 4.24) and neonatal (OR 1.98, $95 \% \mathrm{Cl} 1.43$ to 2.72 ) periods compared with the infant (OR 1.18, 95\% Cl 1.0 to 1.38) and under-5 (OR 1.20, $95 \% \mathrm{Cl} 1.04$ to 1.39 ) periods.

Conclusions: Proximity to health facilities appears to be an important determinant of under-5 mortality in low- and middle-income countries, especially in the perinatal and neonatal periods. Higher quality studies are needed, which examine the effect of access to health services on child survival, especially studies from remote areas and hard to reach populations.

\section{ARTICLE SUMMARY}

Article focus

- Only one previous study has reviewed the relationship between access to healthcare and under-5 mortality. This study did not attempt to pool data or perform a meta-analysis.

- This is the first meta-analysis that has reported associations between proximity to health services and child survival in low- and middleincome countries. We also assessed publication bias and quality of included studies.

\section{Key messages}

- Only a limited number of studies fulfilled our inclusion criteria. However, proximity to health services did appear to have a significant effect on child survival. This effect was stronger in perinatal and neonatal periods compared with infant and under-5 periods.

- The effect of proximity to health services did not appear to differ by region (Africa vs Asia) or by vaccine coverage at the country level.

Strengths and limitations of the study

- The strengths of the study include the detailed search strategy to find all eligible articles, the detailed investigations into sources of heterogeneity.

- Only a limited number of studies fulfilled our inclusion criteria, thus we were unable to perform a multivariable meta-regression analysis. However, we were able to perform detailed univariable analyses and assess the effect of important explanatory variables.

\section{INTRODUCTION}

Each day more than 20000 children under the age of 5 die globally. ${ }^{1}$ Nearly all of these deaths take place in low- and middle-income countries, ${ }^{2}$ and most could be prevented with interventions delivered through health facilities. ${ }^{3}$

There have been many studies that have investigated socio-demographic determinants, use of child health services and child 
mortality in low- and middle-income countries. ${ }^{4} 5$ However, there have been few studies that have examined the barriers to accessing health services, such as distance to health facilities in low- and middle-income countries. There is also little information from remote locations or the poorest countries with low gross national income per capita (GNI).

Important effects of proximity to health services on maternal health outcomes have been described in a number of systematic reviews. ${ }^{6-8}$ However, only one study has reviewed the relationship between access to healthcare and under-5 mortality. ${ }^{9}$ This study described traditional (distance to health services and cost of healthcare access) and non-traditional (social networks, time availability and female autonomy) measures but did not attempt to pool data or perform a meta-analysis. This study also did not assess the effect of health system barriers, such as GNI or rural and remote location. There also has been no systematic review of the effect of proximity to child health services on mortality in specific age categories. These data are needed to plan child health systems in hard to reach poor communities in low- and middle-income countries.

Thus, our primary objective was to estimate the effect of proximity to health facilities on child survival in lowand middle-income countries. The secondary objective was to compare effects in different age categories (perinatal (28 weeks of gestation to 1 week of age), neonatal (0-27 days), infant (0-11 months), child (0-59 months) mortality).

\section{METHODS}

This study was conducted using the PRISMA (Preferred Reporting Items for Systematic Reviews and Metaanalyses) guidelines. ${ }^{10}$

\section{Inclusion criteria}

All studies (longitudinal/cohort, case-control and cross-sectional) that examined the associations between distance to health services and child mortality were reviewed. There were no language restrictions. Studies were excluded if they did not report on: original data (eg, editorials, reviews); all-cause child mortality (eg, studies that only reported on cause-specific mortality were excluded); children under the age of 5; an effect size (eg, OR, RR, HR) of the association between proximity to health facilities and child mortality; and if they were conducted in a high-income country. Studies were excluded from the meta-analysis if they did not include a multivariable analysis and if they did not specify the exact age at death (eg, perinatal mortality, neonatal mortality, infant mortality and under5 mortality).

Figure 1 Flow diagram of search strategy.

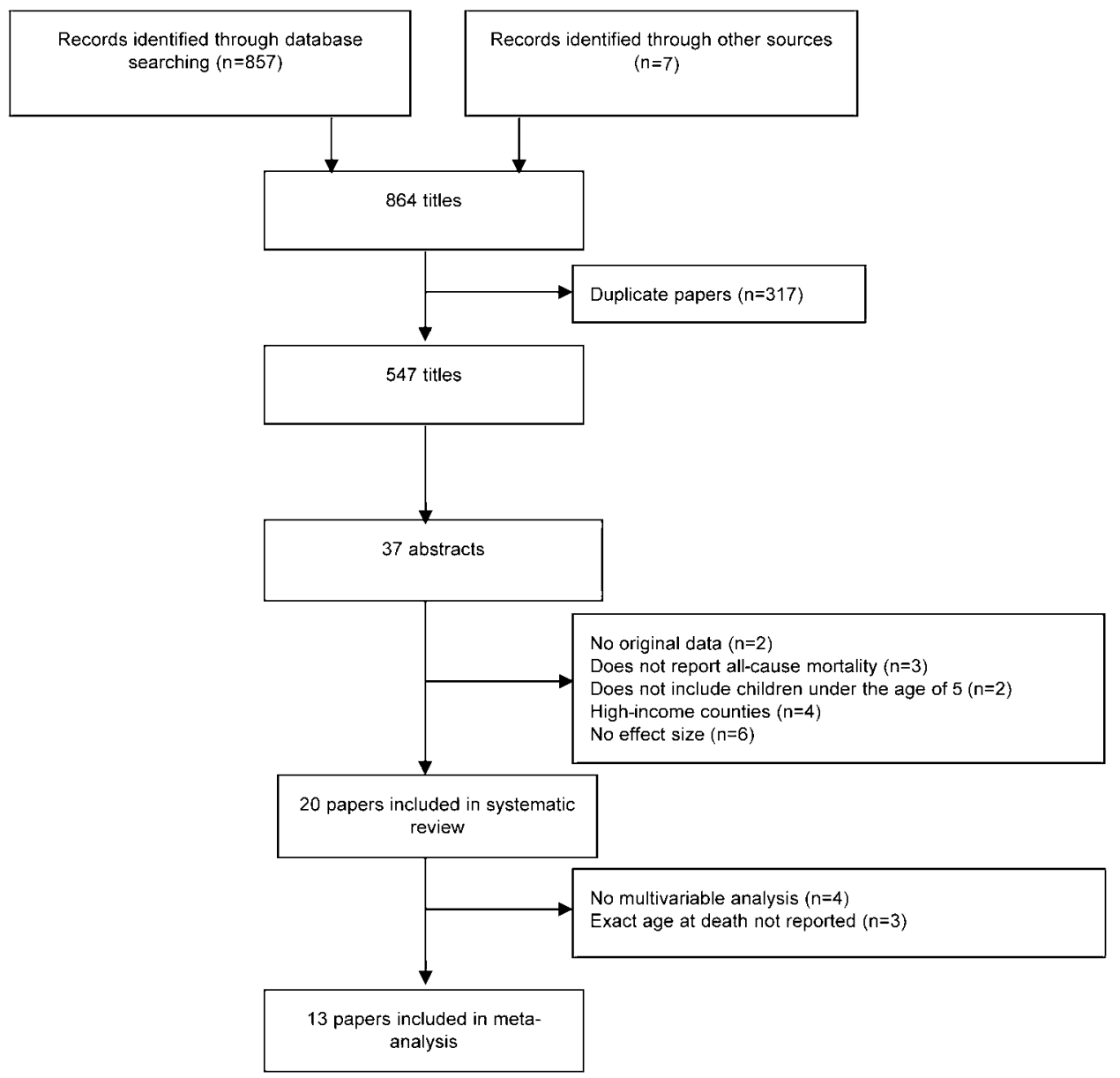




\section{Search strategy}

We searched PubMed, Embase, Medline, Global Health, Cab Abstract, Web of Science and Africa Wide Information to identify studies. The search was limited to literature published between the years 1980 and 2012. We also reviewed the reference lists of all eligible studies.

The initial search aimed to be as inclusive as possible using search terms: ([newborn* OR babies OR infant* OR perinat* OR neonat* OR postneonat* pre-school OR child* OR under-five] AND [death* OR dead OR died OR mortalit* OR surviv*] AND [distance OR travel time OR geographi*] and [Access OR barrier] [Subheading] Limits: Human, 0101 1980-02 01 2012]).

All titles and abstracts were reviewed independently by two reviewers. Papers likely to contain information on proximity to health services and child survival were then examined (figure 1). Studies were then appraised for methodological quality using an adaptation of the Downs and Black scoring system. ${ }^{11}$

\section{Data extraction}

The following information was extracted from every eligible study: key identifiers (author, publication year, title, country of origin), study characteristics (aim, research setting, target population, sample size), study methods (design, exposures, outcomes, variables included in multivariable analyses) and results (effect size (OR, HR, RR) 95\% CI, SE).
We also collected data on potential explanatory variables, that is, variables that may explain variance in effect size. For each study, categories for explanatory variables were created after an initial review of the data as follows: age at death (perinatal, neonatal, infant, under-5), study design (prospective, retrospective), type of access measure (distance from health facility in kilometres $(<5 \mathrm{~km}, \geq 5 \mathrm{~km})$, travel time in hours $(<0.5 \mathrm{~h}, \geq 0.5 \mathrm{~h}))$. Access measures were also categorised as underrepresentative, representative and over-representative. For example, if a study categorised a distance measure as $<5 \mathrm{~km}$ versus $\geq 5 \mathrm{~km}$, it was classified as representative, and if a study categorised a distance measure as $<3 \mathrm{~km}$ versus $\geq 3 \mathrm{~km}$, it was classified as under-representative. Study location (rural non-remote, rural remote, urban) was categorised using the Accessibility/Remoteness Index of Australia (ARIA) rural remote index. ${ }^{12}$ We also used data obtained from the $2010 \mathrm{WHO}^{13}$ and World Bank data sets ${ }^{14}$ to divide countries into WHO region (African, South East Asian, Western Pacific, Eastern Mediterranean, European and American regions) and GNI band in \$US per capita (low income, low middle income, high middle income, high income). There were no data available from the papers on the quality of the health centres or system, thus we decided to use the WHO/Unicef 2010 measles vaccine coverage data $(<80 \%, \geq 80 \%)^{11}$ to provide an indication of health system functioning for children younger than 5 years.

Table 1 Characteristics of studies included in the meta-analysis, 1980-2012

\begin{tabular}{|c|c|c|c|c|c|}
\hline & $\begin{array}{l}\text { Perinatal } \\
(n=2)\end{array}$ & $\begin{array}{l}\text { Neonatal } \\
(n=2)\end{array}$ & $\begin{array}{l}\text { Infant } \\
(n=4)\end{array}$ & $\begin{array}{l}\text { Under-5 } \\
(n=5)\end{array}$ & $\begin{array}{l}\text { Total } \\
(n=13)\end{array}$ \\
\hline \multicolumn{6}{|l|}{ Study design } \\
\hline Prospective & - & $2(100 \%)$ & $2(50 \%)$ & $2(40 \%)$ & $6(46 \%)$ \\
\hline Retrospective & $2(100 \%)$ & - & $2(50 \%)$ & $3(60 \%)$ & 7 (54\%) \\
\hline \multicolumn{6}{|l|}{ Access measure } \\
\hline Distance $(\mathrm{km} / \mathrm{m})$ & $2(100 \%)$ & $2(100 \%)$ & $4(100 \%)$ & $3(60 \%)$ & $11(85 \%)$ \\
\hline Travel time (h/min) & - & - & - & $2(40 \%)$ & $2(15 \%)$ \\
\hline \multicolumn{6}{|l|}{ Access category } \\
\hline $\begin{array}{l}\text { Under } \\
\text { representative }\end{array}$ & - & $1(50 \%)$ & $1(25 \%)$ & $2(40 \%)$ & $4(31 \%)$ \\
\hline Representative & $2(100 \%)$ & $1(50 \%)$ & $2(50 \%)$ & $3(60 \%)$ & $8(62 \%)$ \\
\hline Over representative & - & - & $1(25 \%)$ & - & $1(7 \%)$ \\
\hline \multicolumn{6}{|l|}{ Gross national income } \\
\hline Low income & $1(50 \%)$ & $1(50 \%)$ & $4(100 \%)$ & $5(100 \%)$ & $11(84 \%)$ \\
\hline Lower middle income & $1(50 \%)$ & $1(50 \%)$ & - & - & $2(16 \%)$ \\
\hline Upper middle income & - & - & - & - & - \\
\hline \multicolumn{6}{|c|}{ Vaccine coverage (measles) } \\
\hline$<80 \%$ & $2(100 \%)$ & $1(50 \%)$ & $2(50 \%)$ & $1(20 \%)$ & $6(46 \%)$ \\
\hline$\geq 80 \%$ & - & $1(50 \%)$ & $2(50 \%)$ & $4(80 \%)$ & $7(54 \%)$ \\
\hline \multicolumn{6}{|l|}{ Study location } \\
\hline Rural remote & - & - & - & - & - \\
\hline Rural non-remote & $2(100 \%)$ & $2(100 \%)$ & $4(100 \%)$ & $5(100 \%)$ & $13(100 \%)$ \\
\hline Urban & - & - & - & - & - \\
\hline \multicolumn{6}{|l|}{ Region } \\
\hline African & $1(50 \%)$ & $1(50 \%)$ & $3(80 \%)$ & $5(100 \%)$ & $10(76 \%)$ \\
\hline Asian & $1(50 \%)$ & $1(50 \%)$ & $1(20 \%)$ & - & $3(24 \%)$ \\
\hline
\end{tabular}




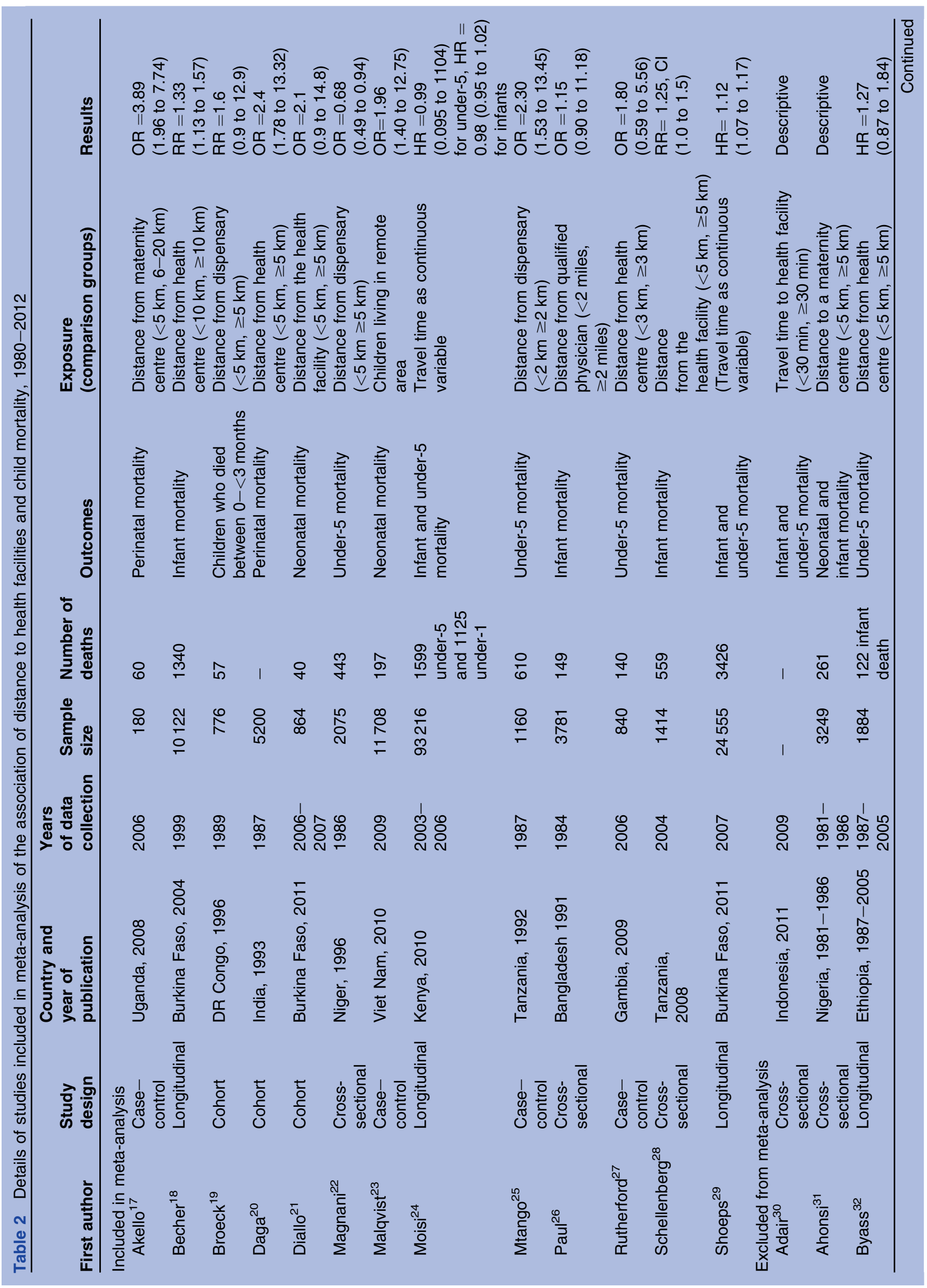




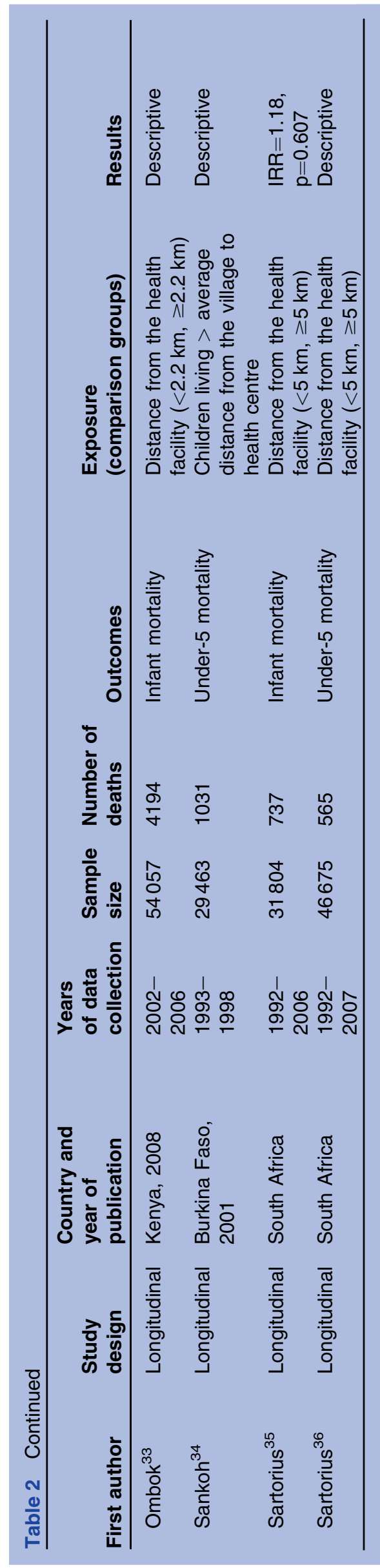

We also planned to divide studies according to the type of care provided in the health facilities (eg, preventive care, acute care, emergency services). However, the health facilities were not described in sufficient detail. Where data were reported for multiple time periods, the most recent data were used.

\section{Statistical analysis}

Our initial review indicated that effect sizes were heterogeneous and influenced by age at death. Thus, we decided to present risks stratified into four mortality categories (perinatal, neonatal, infant, under-5) and to use random-effects meta-analytic techniques to estimate pooled ORs within these strata. Mortality is a rare outcome, thus HRs and RRs were considered to approximate ORs in all studies.

Meta-regression analytic techniques were used to investigate the effect of age at death and other explanatory variables on the pooled estimates. Crude ORs and 95\% CIs were calculated. ${ }^{15}$ We planned to perform multivariable meta-regression analyses, but final models could not be constructed because the number of studies was too small. The risk of publication bias was assessed using Egger's test. ${ }^{16}$ Statistical analyses were performed using STATA Release 12 statistical software (Stata, College Station).

\section{RESULTS}

\section{Search results}

We identified 864 studies published between 1 January 1980 to 1 February 2012 (figure 1). Eight hundred and fifty-seven were obtained from the database sources and seven were obtained from other sources (two were from reference lists and five from other sources). Five hundred and forty-seven studies remained after removing duplicates. The titles of these studies were all reviewed and 510 did not meet the inclusion criteria. Thirty-seven abstracts were reviewed, but only 20 papers were considered eligible for inclusion in our systematic review (figure 1). Thirteen studies were included in the meta-analysis. Characteristics of the 13 included studies are presented in table 1 , and full details can be found in tables 2 and 3 . Overall, 152645 children were included (median number of children per study $=2015$, IQR 180-93216) and 9748 died. One study was conducted in the Western Pacific region (Vietnam), two studies were conducted in the South East Asian region (Bangladesh and India) and the remaining 10 were conducted in the African region (Gambia, Kenya, Tanzania, Uganda, Niger, Nigeria, and DR Congo). Seven studies reported data on under-5 mortality, ${ }^{22} 242527293037 \quad 10$ examined infant mortality, ${ }^{19} 242628-31333537$ six examined neonatal and perinatal mortality. ${ }^{17} 2021233132$ Three studies reported more than one type of mortality outcome.

Results of the quality assessment are displayed in figure 2. Full details can be found in tables S1 and S2 in the supplementary information. Overall, the proportion of studies meeting each quality assessment criteria 
Table 3 Effect of explanatory variables on the association between proximity to health facilities and child survival

\begin{tabular}{|c|c|c|c|c|c|}
\hline & Studies & $\begin{array}{l}\text { Participants } \\
\text { (total No. of } \\
\text { children) }\end{array}$ & $\begin{array}{l}\text { Subgroup estimates; } \\
\text { OR }(95 \% \mathrm{Cl})\end{array}$ & $\begin{array}{l}\text { Univariable regression, } \\
\text { OR }(95 \% \mathrm{Cl})\end{array}$ & $\mathbf{p}$ \\
\hline \multicolumn{6}{|l|}{ Age category } \\
\hline Under-5 & 5 & 121846 & $1.20(1.04$ to 1.39$)$ & 1 & \multirow[t]{4}{*}{0.045} \\
\hline Infant & 4 & 16093 & $1.18(1.00$ to 1.38$)$ & $0.89(0.56$ to 1.42$)$ & \\
\hline Neonatal & 2 & 12572 & $1.98(0.95$ to 1.49$)$ & 1.50 (0.75 to 2.98$)$ & \\
\hline Perinatal & 2 & 2134 & 2.76 (1.80 to 4.24$)$ & 2.12 (1.11 to 4.02$)$ & \\
\hline \multicolumn{6}{|l|}{ Study design } \\
\hline Prospective & 6 & 132744 & $1.22(1.07$ to 1.40$)$ & 1 & \multirow[t]{2}{*}{0.249} \\
\hline Retrospective & 7 & 19901 & 1.69 (1.19 to 2.41$)$ & $1.22(0.73$ to 2.05$)$ & \\
\hline \multicolumn{6}{|l|}{ Access measure } \\
\hline Distance (km) & 11 & 34874 & 1.65 (1.32 to 2.06$)$ & 1 & \multirow[t]{2}{*}{0.051} \\
\hline Travel time (h) & 2 & 117771 & $1.05(0.93$ to 1.19$)$ & $0.63(0.36$ to 1.11$)$ & \\
\hline \multicolumn{6}{|l|}{ Access category } \\
\hline Under-representative & 4 & 17489 & $1.23(0.86$ to 1.77$)$ & 1 & \multirow[t]{3}{*}{0.896} \\
\hline Representative & 8 & 125034 & $1.39(1.20$ to 1.61$)$ & 1.27 (0.69 to 2.32$)$ & \\
\hline Over-representative & 1 & 10122 & 1.33 (1.13 to 1.57$)$ & 1.06 (0.38 to 2.96$)$ & \\
\hline \multicolumn{6}{|l|}{ Region } \\
\hline African & 11 & 135202 & $1.22(1.10$ to 1.35$)$ & 1 & \multirow[t]{2}{*}{0.518} \\
\hline Asian & 2 & 17443 & $1.55(0.79$ to 3.01$)$ & 1.1 (0.59 to 1.97$)$ & \\
\hline \multicolumn{6}{|l|}{ Study location } \\
\hline Rural remote & - & - & - & - & \\
\hline Rural non-remote & 13 & 152645 & - & - & \\
\hline Urban & - & - & - & - & \\
\hline \multicolumn{6}{|l|}{ Gross national income } \\
\hline Low income & 11 & 138983 & $1.27(1.12$ to 1.45$)$ & 1 & \multirow[t]{3}{*}{0.069} \\
\hline Lower-middle income & 2 & 13662 & 2.19 (1.74 to 2.76$)$ & $1.57(0.83$ to 2.94$)$ & \\
\hline Upper middle income & - & - & - & - & \\
\hline \multicolumn{6}{|c|}{ Measles vaccine coverage } \\
\hline$<80 \%$ & 6 & 38451 & 1.71 (1.26 to 2.31$)$ & 1 & \multirow[t]{2}{*}{0.418} \\
\hline$\geq 80 \%$ & 7 & 114194 & $1.35(1.04$ to 1.75$)$ & $1.25(0.76$ to 2.15$)$ & \\
\hline
\end{tabular}

ranged from $5 \%$ to $100 \%$. Most studies had clear objectives, documented selection criteria, provided a representative sample, defined the exposure/characteristics of participants under study and used appropriate statistical tests. However, some studies did not meet a number of other quality assessment criteria. Forty per cent reported a sample size calculation and only a third described potential selection bias. Fifty per cent described potential confounders and only a third adjusted for these potential confounders. Also, only $5 \%$ reported losses to follow-up, and only one made any adjustments for them in the analysis. Also, to assess whether any publication bias was likely, we performed funnel plots of the $\log$ OR against $\mathrm{SE}$ and a clear correlation was found $(\mathrm{p} \leq 0.0001)$.

\section{Mortality estimates}

Overall, proximity to health facilities appeared to have a significant effect on child survival (pooled OR 1.31, $95 \%$ CI 1.17 to 1.45 ) in the pooled 13 studies (figure 3 ). However, there was substantial heterogeneity between studies $\left(\mathrm{p} \leq 0.0001, \mathrm{I}^{2}=89.1 \%\right)$. The stratified analyses indicated that there was a strong effect of proximity to health services on perinatal (summary OR 2.76, 95\% CI
1.80 to 4.24 ) and neonatal mortality (summary OR 1.98, $95 \%$ CI 1.43 to 2.72 ) and no between-study heterogeneity (figure 3). Weak associations were detected for infant (summary OR $1.18,95 \%$ CI 1.00 to 1.38 ) and under-5 mortality (summary OR 1.20 , 95\% CI 1.04 to 1.39), with substantial between-study heterogeneity $\left(\mathrm{p} \leq 0.0001 ; \mathrm{I}^{2}=88.0 \%\right.$ ) (figure 3$)$.

\section{Explanatory factors}

Table 3 shows the results from the crude and adjusted meta-regression analysis of the effect of important factors (age category, study design, access measures, GNI, region, vaccine coverage) that were likely to predict variation in the effect size in the studies. The only factor that was significantly predictive was age at death. The effect of proximity to health services on mortality was significantly stronger during the perinatal period compared with the under-5 period (OR 2.12, 95\% CI 1.11 to 4.02); effects also appeared important in the neonatal period; however, this result was not statistically significant (OR 1.50, 95\% CI 0.75 to 2.98).

The effect of proximity to health services also appeared stronger in studies from countries with higher GNI (OR) and in countries with higher vaccine coverage 


$\begin{array}{llll}\text { Perinatal mortality } & & & \\ \text { Akello }^{17} & 2006 & \text { Uganda } & 180 \\ \text { Daga }^{20} & 1987 & \text { India } & 1954\end{array}$

Subtotal (l-squared $=36.2 \%, p=0.210)$

Neonatal mortality

Diallo ${ }^{21} \quad 2007 \quad$ Birkina Faso $\quad 864$

Malqvist $^{23} \quad 2009$ Vietnam 11708

Subtotal (l-squared $=0.0 \%, p=0.893)$

Infant mortality

Schellenberg ${ }^{28} \quad 2004 \quad$ Tanzania $\quad 1414$

Paul $^{26} \quad 1984 \quad$ Bangladesh 3781

Becher $^{18} \quad 1999$ Burkina Faso 10122

Broeck $^{19} \quad 1989 \quad$ DR Congo $\quad 776$

Subtotal (I-squared $=62.8 \%, p=0.045$ )

Under-five mortality

$\begin{array}{llll}\text { Schoeps }^{29} & 2007 & \text { Burkina Faso } & 24555 \\ \text { Rutherford }^{27} & 2006 & \text { Gambia } & 840 \\ \text { Moisi }^{24} & 2006 & \text { Kenya } & 93216 \\ \text { Magnani }^{22} & 1985 & \text { Niger } & 2075 \\ \text { Mtango }^{25} & 1987 & \text { Tanzania } & 1160\end{array}$

Subtotal (1-squared $=88.0 \%, p=0.000)$

Overall (1-squared $=87.9 \%, p=0.000$ )

4

$x^{2}$

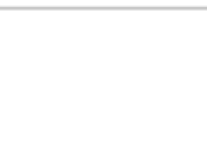

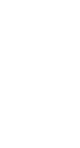

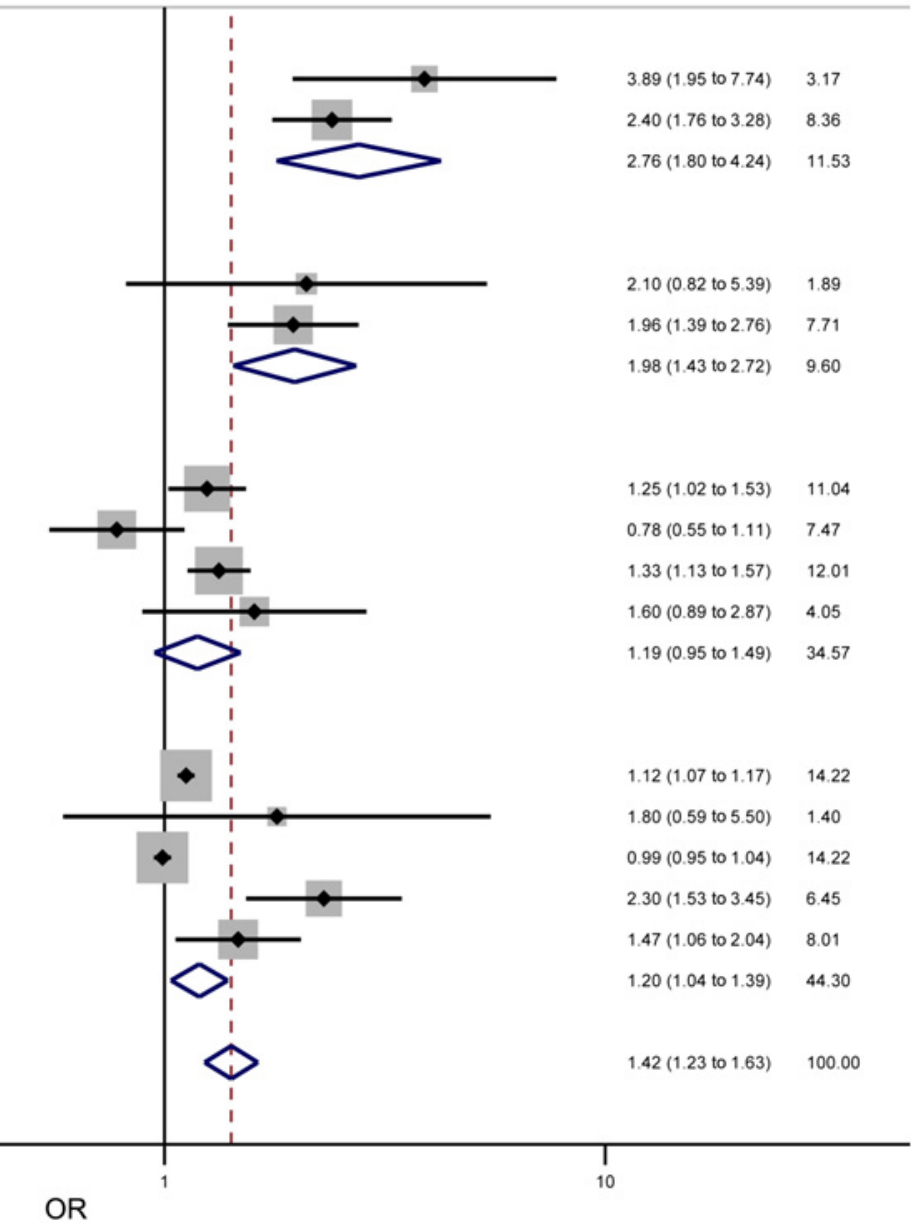

Figure 2 Meta-analysis of the association between proximity to health centres and child survival in 13 studies, 1980-2012.

(OR). However, these results were not statistically significant. The effect of study location (remote, rural, urban) could not be studied as there were no remote or urban studies included in the analysis. A multivariable analysis also could not be performed due to insufficient study numbers.
Figure 3 Proportion of studies meeting the quality assessment criteria.

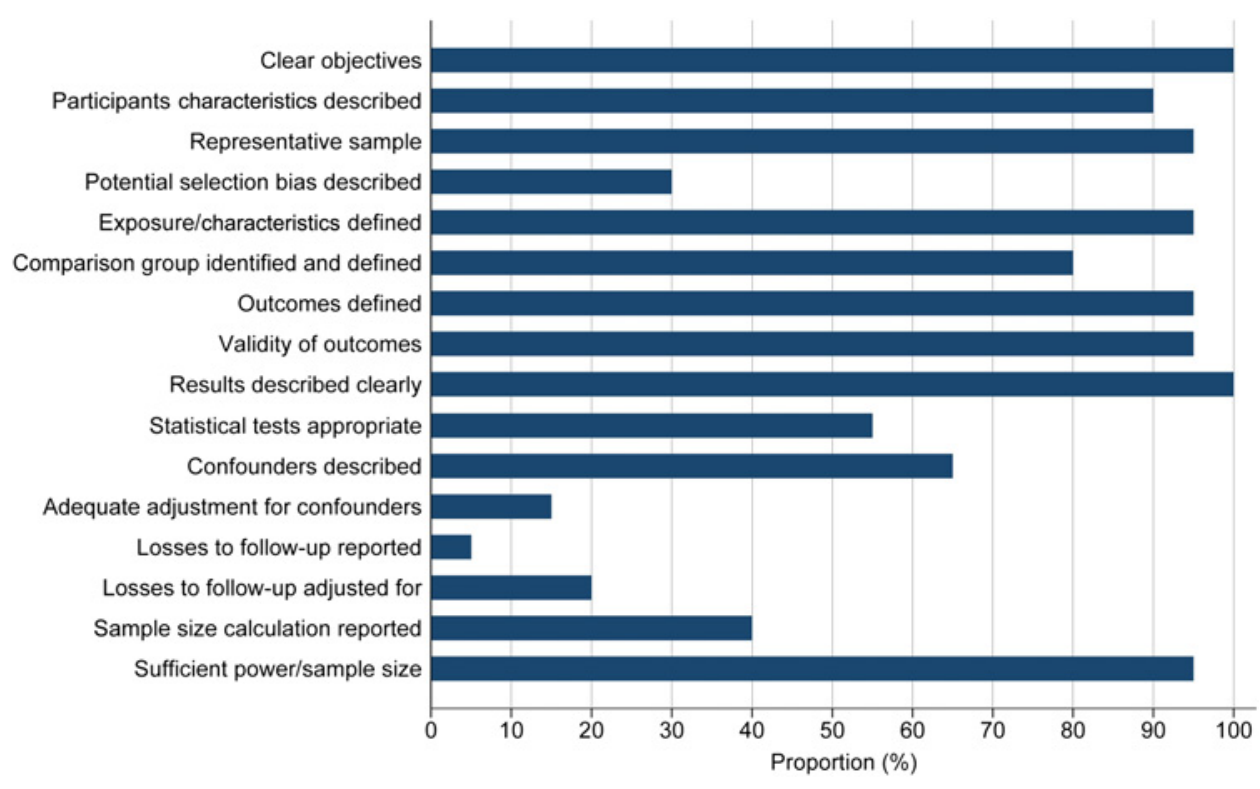




\section{DISCUSSION}

Our study demonstrated that proximity to health facilities is an important determinant of under- 5 mortality in low- and middle-income countries especially in the perinatal and neonatal periods. Proximity to health facilities appeared to be more important in countries with well-functioning health systems and higher GNI.

This is the first systematic review that has reported associations between proximity to health facilities and child survival. The studies included in our meta-analysis indicated that children living within $5 \mathrm{~km}$ or $30 \mathrm{~min}$ travel time from a health centre had a decreased perinatal and neonatal mortality risk compared with children who lived further away. However, only a limited number of studies fulfilled our inclusion criteria. Data were also heterogeneous and inconclusive for older infants and children. There has been only one other systematic review that has examined the relationship between access to healthcare and under-5 mortality. ${ }^{9}$ This study was limited to sub-Saharan Africa and indicated that distance to health services and cost of healthcare access were likely to be important but did not attempt to pool data or specify effects by age at death. In contrast, there have been many systematic reviews reporting the influence of distance to health services on maternal health outcomes. ${ }^{6-8}$ These studies indicate that there are strong links between emergency obstetric care services and maternal health outcomes and that well-functioning referral systems are also needed.

We also reported that proximity to health facilities was associated with stronger effects in richer countries with well-functioning health systems than poorer countries. This is likely to be due to the better quality of healthcare provided in the facilities in the richer countries. However, most studies included in our meta-analysis did not describe the type or quality of healthcare provided in the facilities, thus we were not able to examine the impact of quality of care on child mortality outcomes. Indicators have recently been developed for monitoring progress in quality of neonatal and child healthcare in low- and middle-income countries. ${ }^{38}$ Further studies should be conducted using these indicators to describe quality as well as access to care.

Interestingly, the effect of proximity to health centres did not appear to differ between Asian and African countries despite the great differences in healthcare provided in these regions. However, there were no studies from the Eastern Mediterranean, American or European regions, and information about proximity to healthcare and child survival in these regions is urgently needed. We also planned a priori to examine effects in remote and hard to reach populations. However, no studies in our meta-analysis were located in populations classified as remote.

Overall, the quality of the included studies was good. Most studies had clear objectives, documented selection criteria, provided a representative sample, defined the exposure/characteristics of participants under study and used appropriate statistical tests. However, few studies adjusted for these potential confounders and only $5 \%$ reported losses to follow-up.

Our review had some limitations. First, only a limited number of studies fulfilled our inclusion criteria, thus we were unable to perform a multivariable meta-regression analysis. However, we were able to perform detailed univariable analyses and assess the effect of important explanatory variables. Second, the variability in the access measure (ie, distance in kilometres, travel time in hours) and in the categories chosen limited the comparability of the studies. No studies incorporated topography and terrain in their access measurement or used more sophisticated measures of modelling travel time. However, in nine of 13 studies, the same categories were used $(<5 \mathrm{~km}$ vs $\geq 5 \mathrm{~km}$ and $<0.5 \mathrm{~h}$ vs $\geq 0.5 \mathrm{~h})$ and results appeared similar in the stratified meta-analysis and meta-regression analyses. Third, there was marked heterogeneity in the studies included in the infant and under-5 mortality analyses. However, the age-specific stratified analyses for perinatal and neonatal mortality were very homogeneous. Also there appeared to be an interesting gradation of effect; most marked for perinatal, followed by neonatal and least for infant and under-5 mortality. Additional studies that examine effects at these different ages are needed.

Our article has important implications for policy and programme development. We reported that proximity to health facilities is an important determinant of mortality in low- and middle-income countries in the perinatal and neonatal periods but not in the postneonatal period. Proximity to health facilities appeared to be most important in countries with well-functioning health systems, regardless of GNI. Children and families require better access to health services in low- and middleincome countries especially during the perinatal and neonatal periods. Higher quality studies are needed, which examine the effect of access to health services on child survival in low- and middle-income countries, especially studies from remote areas and hard to reach populations.

Acknowledgements We acknowledge the contribution of Tieble Traore in assisting with data abstraction.

Contributors All authors contributed to conception and design of the review. All authors performed the abstraction and analysis of the data. All authors drafted and revised the manuscript. All authors read and approved the final version of the manuscript.

Funding YBO was funded by the Research Council Norway (grant number 190257). The funders played no role in the study design, collection, analysis, interpretation of data, writing of report or in the decision to submit the paper for publication. They accept no responsibility for the contents.

Competing interests None.

Provenance and peer review Not commissioned; externally peer reviewed.

Data sharing statement All original data extraction are available from the corresponding author at yemisrach.okwaraji@|shtm.ac.uk. Full details on quality assessment are available in the supplemental documents submitted with this article. 


\section{REFERENCES}

1. UNICEF. The State of the World's Children 2008. 2009. http://www. unicef.org/sowc08/ (accessed 15 Jan 2012).

2. Murray CJ, Laakso T, Shibuya K, et al. Can we achieve Millennium Development Goal 4? New analysis of country trends and forecasts of under-5 mortality to 2015. Lancet 2007;370:1040-54.

3. Jones G, Steketee RW, Black RE, et al. Child survival II How many child deaths can we prevent this year? Lancet 2003;362:65-71.

4. Hammer GP, Kouyaté B, Ramroth $\mathrm{H}$, et al. Risk factors for childhood mortality in sub-Saharan Africa. A comparison of data from a demographic and health Survey and from a demographic Surveillance system. Acta Trop 2006;98:212-18.

5. Habib NA, Lie RT, Oneko O, et al. Sociodemographic characteristics and perinatal mortality among singletons in North East Tanzania: a registry-based study. J Epidemiol Community Health 2008;62:960-5.

6. Gabrysch S, Campbell OM. Still too far to walk: literature review of the determinants of delivery service use. BMC Pregnancy Childbirth 2009;9:34

7. Say L, Raine R. A systematic review of inequalities in the use of maternal health care in developing countries: examining the scale of the problem and the importance of context. Bull World Health Organ 2007:85:812-19.

8. Thaddeus S, Maine D. Too far to walk: maternal mortality in context. Soc Sci Med 1994;38:1091-110.

9. Rutherford ME, Mulholland K, Hill PC. How access to health care relates to under-five mortality in sub-Saharan Africa: systematic review. Trop Med Int Health 2010;15:508-19.

10. Liberati A, Altman DG, Tetzlaff J, et al. The PRISMA statement for reporting systematic reviews and meta-analyses of studies that evaluate health care interventions: explanation and elaboration. PLoS Med 2009;6:e1000100.

11. Downs SH, Black N. The feasibility of creating a checklist for the assessment of the methodological quality both of randomised and non-randomised studies of health care interventions. $J$ Epidemiol Community Health 1998;52:377-84.

12. AlHW. Rural, Regional and Remote Health: A Guide to Remoteness Classifications. 2004. http://www.aihw.gov.au/publication-detail/? $\mathrm{id}=6442467589$ (accessed 22 Feb 2012).

13. WHO. List of Member States by WHO Region and Mortality Stratum. 2003. http://www.who.int/whr/2003/en/member_states_182-184_en. pdf (accessed 22 Feb 2012).

14. World Bank. Worldbank. http://data.worldbank.org/indicator/NY.GNP. PCAP.CD (accessed 20 Feb 2012).

15. Higgins JP, Thompson SG. Controlling the risk of spurious findings from meta-regression. Stat Med 2004;23:1663-82.

16. Egger M, Smith DG, Altman DG. Systematic Reviews in Health Care: Meta-Analysis in Context, Second Edition. 2008.

17. Akello B, Nabiwemba E, Zirabamuzaale C, et al. Risk factors for perinatal mortality in Arua regional referral hospital, West Nile, Uganda. East Afr J Public Health 2008;5:180-5.

18. Becher $\mathrm{H}, \mathrm{Müller} \mathrm{O}$, Jahn $\mathrm{A}$, et al. Risk factors of infant and child mortality in rural Burkina Faso. Bull World Health Organ 2004;82:265-73.

19. Van den Broeck J, Eeckels R, Massa G. Maternal determinants of child survival in a rural African community. Int $J$ Epidemiol 1996;25:998-1004.
20. Daga AS, Daga SR. Epidemiology of perinatal loss in rural Maharashtra. J Trop Pediatr 1993;39:83-5.

21. Diallo $\mathrm{AH}$, Meda N, Ouédraogo WT, et al. A prospective study on neonatal mortality and its predictors in a rural area in Burkina Faso: can MDG-4 be met by 2015? J Perinatol 2011;31:1-8.

22. Magnani RJ, Rice JC, Mock NB, et al. The impact of primary health care services on under-five mortality in rural Niger. Int $J$ Epidemiol 1996;25:568-77.

23. Målqvist $\mathrm{M}$, Sohel $\mathrm{N}$, Do $\mathrm{TT}$, et al. Distance decay in delivery care utilisation associated with neonatal mortality. A case referent study in northern Vietnam. BMC Public Health 2010;10:762.

24. Moïsi JC, Gatakaa H, Noor AM, et al. Geographic access to care is not a determinant of child mortality in a rural Kenyan setting with high health facility density. BMC Public Health 2010;10:142.

25. Mtango FD, Neuvians D, Broome CV, et al. Risk factors for death in children under 5 years old in Bagamoyo district, Tanzania. Trop Med Parasitol 1992;43:229-33.

26. Paul BK. Health service resources as determinants of infant death in rural Bangladesh: an empirical study. Soc Sci Med 1991;32:43-9.

27. Rutherford ME, Dockerty JD, Jasseh M, et al. Access to health care and mortality of children under 5 years of age in the Gambia: a casecontrol study. Bull World Health Organ 2009;87:216-24.

28. Armstrong Schellenberg JR, Mrisho M, Manzi F, et al. Health and survival of young children in southern Tanzania. BMC Public Health 2008;8:194.

29. Schoeps A, Gabrysch S, Niamba L, et al. The effect of distance to health-care facilities on childhood mortality in rural Burkina Faso. Am $J$ Epidemiol 2011;173:492-8.

30. Adair T, Pardosi JF, Rao C, et al. Access to health services and early age mortality in Ende, Indonesia. Indian J Pediatr 2011;79:1-7.

31. Ahonsi BA. Age variations in proximate determinants of child mortality in south-west Nigeria. J Biosoc Sci 1995;27:19-30.

32. Byass $\mathrm{P}$, Fantahun $\mathrm{M}$, Mekonnen $\mathrm{W}$, et al. From birth to adulthood in rural Ethiopia: the Butajira Birth cohort of 1987. Paediatr Perinat Epidemiol 2008;22:569-74.

33. Ombok M, Adazu K, Odhiambo F, et al. Geospatial distribution and determinants of child mortality in rural western Kenya 2002-2005. Trop Med Int Health 2010;15:423-33.

34. Sankoh OA, Yé Y, Sauerborn R, et al. Clustering of childhood mortality in rural Burkina Faso. Int J Epidemiol 2001;30:485-92.

35. Sartorius BK, Kahn K, Vounatsou P, et al. Young and vulnerable: spatial-temporal trends and risk factors for infant mortality in rural South Africa (Agincourt), 1992-2007. BMC Public Health 2010;10:645.

36. Sartorius B, Kahn K, Collinson MA, et al. Survived infancy but still vulnerable: spatial-temporal trends and risk factors for child mortality in the Agincourt rural sub-district, South Africa, 1992-2007. Geospat Health 2011;5:285-95.

37. Becher $\mathrm{H}$, Müller $\mathrm{O}$, Jahn $\mathrm{A}$, et al. Risk factors of infant and child mortality in rural Burkina Faso. Bull World Health Organ 2004;82:265-73.

38. USAID. Using the Collaborative Approach to Improve Pediatric Hospital Care. 2008. http://www.hciproject.org/node/1070 (accessed 20 Feb 2012). 